\title{
Distribution of Nuclei of Different Ploidy Levels during Ovule, Seed and Protocorm Development in Phalaenopsis aphrodite subsp. formosana (Orchidaceae)
}

\author{
Goamg-Tyng Jean ${ }^{1}$, Yu-Lin Kao ${ }^{1}$, Ching-Yan Tang ${ }^{1}$, Wen-Huei Chen ${ }^{2}$ \\ ${ }^{1}$ Department of Life Sciences \& Institute of Biotechnology, National University of Kaohsiung, Kaohsiung, Taiwan, Chinese Taipei; \\ ${ }^{2}$ Orchid Research Center, National Cheng Kung University, Tainan, Taiwan, Chinese Taipei. \\ Email: wenhueic005@gmail.com, yulinkao@nuk.edu.tw
}

Received April $6^{\text {th }}, 2011$; revised May $8^{\text {th }}, 2011$; accepted June $2^{\text {nd }}, 2011$.

\begin{abstract}
Distribution of nuclei of different ploidy levels was studied at different developmental stages in the embryonic tissue of the ovule, seed and protocorm of Phalaenopsis aphrodite subsp. formosana (Miwa) E.A. Christ by a combination of flow cytometry and fluorescence microscopy with Apo Tome Slider. Three stages of ploidy patterns were identified in the ovular tissue at different days after pollination (DAP). Firstly, between pollination and fertilization (0 to 50 DAP), $2 C$ nuclei were dominant over $4 C$ nuclei and resulted in low level of cycle value. Secondly, between fertilization and seed maturation (50 to 110 DAP), amount of $4 C$ nuclei increased rapidly, maintained at a high level and then decreased gradually to a low level. Small amount of $8 \mathrm{C}$ nuclei was also detected at this stage. Thirdly, at seed maturation (110 to 130 DAP), 2C nuclei became dominant over $4 C$ nuclei again and the cycle value remained at a low but significant level at this stage. After seed sowing, nuclei with ploidy levels of $2 C, 4 C$ and $8 C$ were observed in the developing protocorms as early as at 4 DAS (days after sowing). Nuclei with high ploidy levels (8C and 16C) increased gradually until 40 DAS in this study. Significant level of cycle value at this stage of protocorm development indicated the presence of endopolyploidy. 4,6-diamido-2-phenylindol (DAPI) staining showed large and prominent nuclei in the basal portions of the mature seeds before sowing and in the developing protocorms at 20 DAS. These findings clearly demonstrate the occurrence of different distribution patterns of nuclei with different ploidy levels during ovule, seed and protocorm development in Phalaenopsis aphrodite. These observations will provide fundamental information for further studies in Phalaenopsis orchids.
\end{abstract}

Keywords: Moth Orchid, Phalaenopsis, Endopolyploidy, Ovule, Seed, Protocorm, Flow Cytometry

\section{Introduction}

The normal cell cycle includes different phases such as gap 1 (G1), DNA synthesis (S), gap 2 (G2) and mitosis (M). Throughout the processes of DNA duplication and cell division, the DNA content, or the chromosome number, remains constant from cycle to cycle. Recent research found that a complicated system was involved in the regulation of these phases [1-3]. Furthermore, due to various internal or external factors, the regulation of the cell cycle may be disturbed and resulted in the duplication of nuclear DNA without cell division, which is called endoreduplication $[1,4]$. Due to endoreduplication, cells having different ploidy levels occurred in the same tissue, giving rise to endopolyploidy, which was commonly found in various plant species [5]. This kind of mixture of cells having different ploidy levels in the tissue is also called polysomaty $[6,7]$.

There are different degrees of endopolyploidy in different organs and tissues within a species. In general, the occurrence of endopolyploidy is lower in actively growing tissues and higher in more differentiated tissues [5,8-10]. A high degree of endopolyploidy has also been observed in certain types of highly specialised cells, such as root hairs, trichomes, endosperm, suspensors and antipodal cells $[5,11,12]$. Many reports have shown that the cell volume and nuclear size were correlated with endoreduplication in various plant species $[5,13,14]$. 
Endoreduplication has been reported in some groups of orchids [15-18]. Lee et al. [19] observed that endoreduplication occurred at different stages of floral development in Phalaenopsis aphrodite, Phalaenopsis equestris and Oncidium varicosum. Their study showed that the degree of endoreduplication was positively correlated with the stage of floral development. When the flower had fully expanded, endoreduplication and flower fresh weight had ceased to increase. In addition, cell size was highly correlated to the number of cycles of endoreduplication. Quantitative changes in nuclear DNA content were studied in developing embryos of Vanda sanderiana, using a cytophotometric technique [20]. It was found that DNA content was positively correlated with cell size and with the distance of the nucleus from the meristem of the embryo.

For Phalaenopsis orchids, the pathways of megasporogenesis and microsporogenesis and the structure of the embryo sac are similar to most of the angiosperms [21]. However, pollination is required to stimulate ovary growth, ovule development and megasporogenesis in this orchid. This process may take 40 to 80 days depending on the species [21-23]. After fertilization, seeds with incomplete embryos lacking endosperm are developed. However, information on the occurrence of endopolyploidy during ovule, seed and protocorm development is not available in this orchid.

Flow cytometry and fluorescence microscopy were used in the present study to investigate the distribution of nuclei of different ploidy levels at different developmental stages of the ovule, seed and protocorm in Phalaenopsis aphrodite subsp. formosana (Miwa) E.A. Christ. (syn. Phalaenopsis amabilis var. formosa Shimadzu) to provide fundamental information for further studies in this group of orchids.

\section{Materials and Methods}

\subsection{Plants and Culture Conditions}

Flowering plants of diploid Phalaenopsis aphrodite subsp. formosana purchased from orchid nurseries in Taiwan were grown in a culture room at a temperature of $23^{\circ} \mathrm{C}-25^{\circ} \mathrm{C}$, under white fluorescent light (FL40D, TOA Lighting, Taiwan) with a $16 / 8 \mathrm{~h} \mathrm{~L} / \mathrm{D}$ photoperiod. Selfpollination was carried out to initiate the growth of the ovaries and capsules that were used as materials for this study. Seeds were harvested from the mature capsules and stored at $4^{\circ} \mathrm{C}$.

Before sowing, seeds were surface-sterilised with 5\% Clorox $^{\mathrm{TM}}$ (containing 6\% sodium hypochlorite) for 5 minutes and rinsed three times with sterilised distilled water. Soon after, they were sown on modified Murashige and Skoog (MS) [24] basal medium containing 1/4- strength MS salts $\left(1.1 \mathrm{~g} \cdot \mathrm{dm}^{-3}\right)$, supplemented with 1 $\mathrm{g} \cdot \mathrm{dm}^{-3}$ tryptone, $20 \mathrm{~g} \cdot \mathrm{dm}^{-3}$ sucrose, $65 \mathrm{~g} \mathrm{dm}^{-3}$ homogenised potato and $8.5 \mathrm{~g} \cdot \mathrm{dm}^{-3}$ agar [25]. Petri dishes containing the seeds were placed in darkness in a culture room at $25^{\circ} \mathrm{C} \pm 2{ }^{\circ} \mathrm{C}$ for one week and then cultured at the same temperature with $20 \mu \mathrm{mol} \cdot \mathrm{m}^{-2} \cdot \mathrm{s}^{-1}$ of light provided by white fluorescent lights.

\subsection{Method for Flow Cytometric Analyses of Nuclear DNA Content}

Fresh tissue samples from ovules or protocorms, weighing $10 \mathrm{mg}-40 \mathrm{mg}$, were individually chopped with a sharp razor blade to pieces $<1 \mathrm{~mm}$ in size in a $6-\mathrm{cm}$ glass Petri dish containing $100 \mu \mathrm{dm}^{3}$ extracting buffer (solution A of the CyStain UV Precise P kit, Partec, Münster, Germany). After chopping, $400 \mu \mathrm{dm}^{3}$ of 4,6-Diamidino-2-phenylindol (DAPI) staining buffer (solution B of the kit) were added. The suspension was filtered through a 30- $\mu \mathrm{m}$ nylon mesh (CellTrics ${ }^{\mathrm{TM}}$, Partec). For each sample, 2500 - 5000 nuclei were analysed, using a Partec PA-I (Münster, Germany) flow cytometer equipped with an HBO-100 mercury lamp. To determine the DNA content of the samples, young leaves of in vitro plantlets of diploid Phalaenopsis aphrodite were used as reference for the $2 \mathrm{C}$ DNA content, which is $2.80 \mathrm{pg} 2 \mathrm{C}^{-1}$ [15]. In this study, 1C represents the nuclear DNA content of gametes with 19 chromosomes in Phalaenopsis aphrodite. Ploidy patterns were represented by the distribution of nuclei with different $\mathrm{C}$ values (e.g., 2C, 4C, 8C). $\mathrm{Cy}$ cle values, which indicate the mean numbers of endoreduplication cycles representing the degree of endopolyploidy in the tissue, were calculated after Barow and Meister [10] as follows:

$$
\begin{aligned}
& \text { Cycle value } \\
& =\left(0 \cdot n_{2 \mathrm{C}}+1 \cdot n_{4 \mathrm{C}}+2 \cdot n_{8 \mathrm{C}}+3 \cdot n_{16 \mathrm{C}} \cdots\right) \\
& \quad \div\left(n_{2 \mathrm{C}}+n_{4 \mathrm{C}}+n_{8 \mathrm{C}}+n_{16 \mathrm{C}} \cdots\right)
\end{aligned}
$$

where $n_{2 \mathrm{C}}, n_{4 \mathrm{C}}, n_{8 \mathrm{C}}, n_{16 \mathrm{C}} \cdots$ are the numbers of nuclei with the corresponding $\mathrm{C}$-values $(2 \mathrm{C}, 4 \mathrm{C}, 8 \mathrm{C}, 16 \mathrm{C} \cdots)$.

\subsection{Determination of Nuclear DNA Contents of Ovules and Seeds during Ovary and Capsule Development}

After pollination, developing capsules (Figure 1(a)) were collected at 7-day intervals from 35 days after pollination (DAP) until 99 DAP. Three capsules were studied at each interval. Between 35 and 64 DAP, parts of the harvested capsules were sectioned for microscopic examination, as shown in the last part of this section. The remaining parts of the capsules were dissected longitudinally. The white ovular tissues (Figure 1(b)) on the surfaces of the placentae were carefully removed with a scal- 
pel, for flow cytometric analysis. After 78 DAP, seeds which detached easily from the placentae were collected for the above analysis. From 110 DAP, mature seeds were collected at 10-day interval until 130 DAP.

\subsection{Determination of Nuclear DNA Contents of the Germinating Seeds}

Samples of developing protocorms were collected at 4 , $10,20,30$ and 40 days after sowing (DAS) for microscopic investigation and for the analysis of ploidy pattern by flow cytometry.

\subsection{Microscopic Examination and Nuclear Staining}

Seeds, protocorms and transverse sections (less than $1 \mathrm{~mm}$ thick) of the young capsules were examined under a dis- secting microscope equipped with an image capturing device. Tissues were fixed in a fixative containing $95 \%$ alcohol and glacial acetic acid (3:1, v:v) overnight and then stored in $70 \%$ alcohol for further treatment. Fixed tissues were put in $3-\mathrm{mdm}^{3}$ microcentrifuge tubes containing $1 \mathrm{mdm}^{3}$ of DAPI staining solution (double-distilled water and Partec UV staining buffer, 1:4, v:v). They were then placed in a sealed plastic container evacuated by an air pump, until the air pressure reached $600 \mathrm{mmHg}$ for 40 minutes. The DAPI-stained capsule sections were then examined with an inverted fluorescence microscope (Zeiss Axio Observer). DAPI-stained seeds and protocorms were examined with the same microscope, equipped with an Apo Tome Slider system to obtain serial images of the optical sectioning from the top surface to the bottom of the tissue.
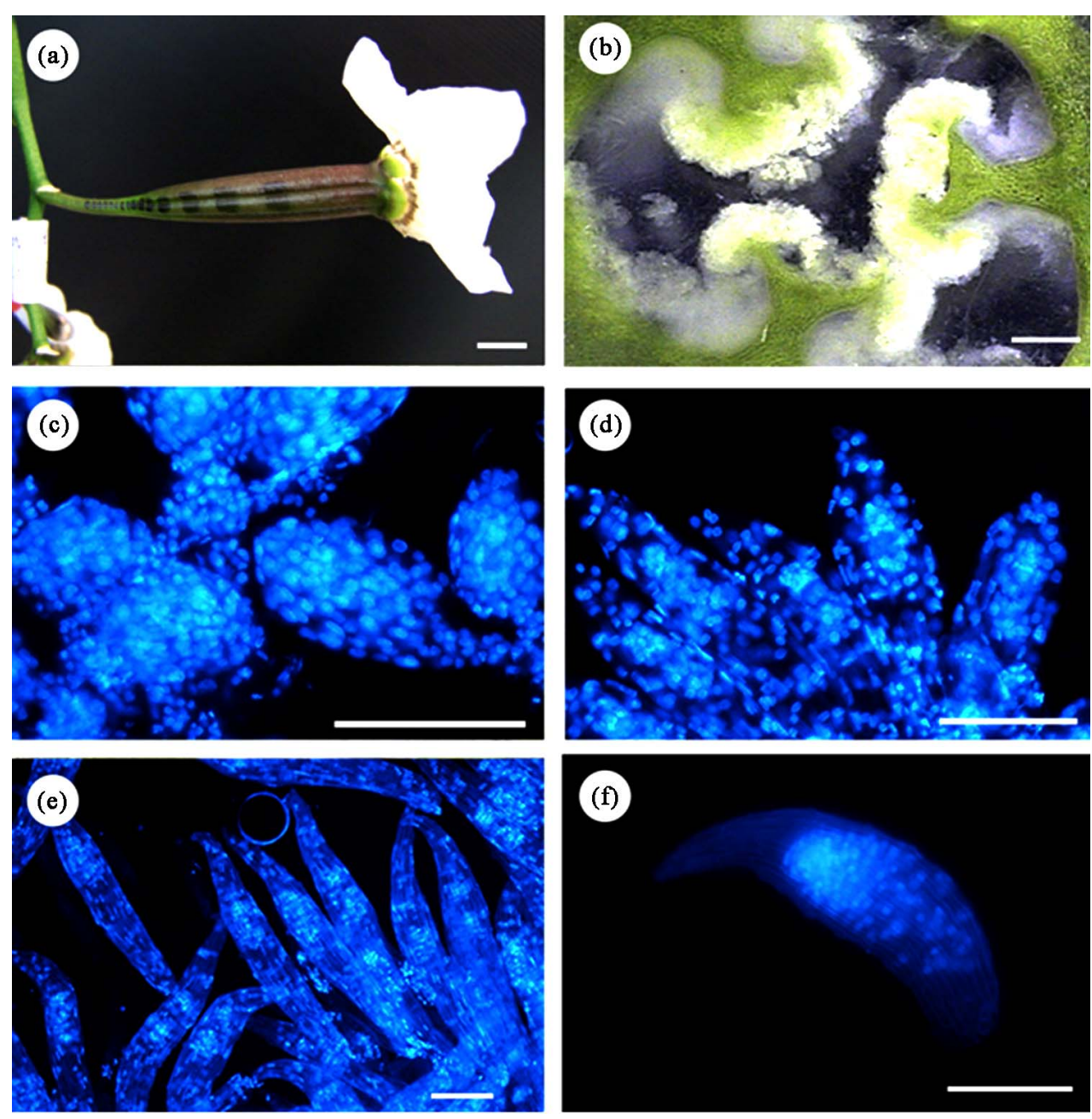

Figure 1. Ovary and developing ovules and seeds inside the ovary of Phalaenopsis aphrodite at different days after pollination (DAP): (a) outer appearance of the ovary at 35 DAP (bar = $1 \mathrm{~cm})$; (b) light micrograph of transverse sections of the ovary at 35 DAP (white tissues are developing ovules) ; (c) DAPI-stained fluorescence micrographs of developing ovules at 50 DAP; (d) developing seeds at 57 DAP; (e) at 78 DAP; (f) at 99 DAP (all bars in micrographs $=100 \mu \mathrm{m}$ ). 


\section{Results}

\subsection{Ovule and Seed Development after Pollination}

After pollination, the ovary of Phalaenopsis aphrodite subsp. formosana grew rapidly for about 40 days, reaching approximately $6 \mathrm{~cm}$ in length and $1 \mathrm{~cm}$ in width (Figure 1(a)). The expansion then slowed down and levelled off. Different stages of ovule development were investigated in free-hand cross-sections with or without DAPI staining and observed under the microscope. At 35 DAP, placentae became fork-like structures with white and loosely arranged tissue on the surface, indicating the development of ovule primordia (Figure 1(b)). At 43 and 50 DAP, the globular structures of mature ovules were observed (Figure 1(c)). At 57 and 78 DAP, these ovules elongated and became seeds with ellipsoidal structures (Figures 1(d) and (e)). At this stage, nuclei were more or less evenly distributed throughout the structures. At 85 DAP, striped coats appeared on the surfaces of seeds, which easily departed from the ends of the placentae. By 92 - 99 DAP, seeds with seed coats and embryos were developed (Figure 1(f)). Nuclei inside the seeds were concentrated in the embryos proper, while the nuclei in the seed coats disappeared at this stage, indicating the occurrence of embryo development. It was also observed that the nuclei of the embryos proper appeared to be unevenly distributed, with more nuclei at one end of the elongated seeds. The seed coats became brownish-yellow by $110-120$ DAP, indicating seed maturation at this stage.

\subsection{Flow Cytometric Analysis of Nuclear DNA Contents during Ovule and Seed Development}

Frequency distributions of nuclei having different ploidy levels were investigated by means of flow cytometry in ovules and seed tissues at different stages of development are shown in Table 1 and Figure 2. Different patterns of distribution at three stages were identified. First, between 35 and 50 DAP, 2C nuclei with high frequency were dominant over 4C nuclei (Figure 2(a)). The 1C nuclei appeared in small numbers at 43 and 50 DAP and then disappeared in the later stages. Second, from 57 to 92 DAP, 4C nuclei increased rapidly and remained at a high level (Figure 2(b)). 8C nuclei were observed at this stage, ranging from $1.48 \%$ to $3.5 \%$. Then the proportion of $4 \mathrm{C}$ nuclei decreased gradually and was replaced by an increase in 2C nuclei until 110 DAP (Figure 2(c)). Third, between 120 and 130 DAP, 2C nuclei remained at high level and became dominant over $4 \mathrm{C}$ nuclei again (Figure 2(d)). $8 \mathrm{C}$ nuclei were observed at very low frequency at this stage of seed maturation. The cycle values, representing the mean numbers of endoreduplication cycles, are shown in Table 1. Cycle values of the ovular tissue were low from 0 to $50 \mathrm{DAP}$, then increased at $57 \mathrm{DAP}$ and remained high until 110 DAP, indicating the occurrence of increased amounts of endoreduplicated nuclei at this stage. Later, these values decreased to a low level at 120 - 130 DAP.

Table 1. Percentages of nuclei with various nuclear DNA contents and cycle value of the ovules and seeds of Phalaenopsis aphrodite at different days after pollination (DAP). All values are means \pm SD of three capsules, each with three observations.

\begin{tabular}{cccccc}
\hline DAP & $1 \mathrm{C}$ & $2 \mathrm{C}$ & $4 \mathrm{C}$ & $8 \mathrm{C}$ & Cycle value $^{\mathrm{a}}$ \\
\hline 35 & 0 & $85.7 \pm 0.9$ & $14.3 \pm 0.9$ & 0 & $0.14 \pm 0.01 \mathrm{e}$ \\
43 & $8.2 \pm 3.2$ & $78.2 \pm 3.9$ & $13.7 \pm 1.4$ & 0 & $0.15 \pm 0.02 \mathrm{e}$ \\
50 & $9.1 \pm 4.1$ & $63.6 \pm 6.4$ & $27.3 \pm 6.0$ & 0 & $0.30 \pm 0.06 \mathrm{~d}$ \\
57 & 0 & $27.6 \pm 5.2$ & $69.6 \pm 3.6$ & $2.8 \pm 2.7$ & $0.75 \pm 0.07 \mathrm{ab}$ \\
64 & 0 & $24.3 \pm 1.7$ & $74.7 \pm 2.0$ & $1.8 \pm 2.2$ & $0.78 \pm 0.03 \mathrm{a}$ \\
71 & 0 & $25.8 \pm 2.9$ & $72.7 \pm 3.3$ & $1.5 \pm 2.3$ & $0.76 \pm 0.04 \mathrm{ab}$ \\
78 & 0 & $28.9 \pm 7.4$ & $68.7 \pm 9.5$ & $2.4 \pm 2.7$ & $0.73 \pm 0.06 \mathrm{ab}$ \\
85 & 0 & $29.7 \pm 8.3$ & $67.7 \pm 9.0$ & $3.5 \pm 3.0$ & $0.73 \pm 0.09 \mathrm{ab}$ \\
92 & 0 & $29.4 \pm 3.6$ & $59.1 \pm 4.9$ & $2.0 \pm 2.9$ & $0.74 \pm 0.04 \mathrm{ab}$ \\
110 & 0 & $38.8 \pm 3.2$ & $48.7 \pm 12.2$ & $1.8 \pm 2.9$ & $0.63 \pm 0.05 \mathrm{bc}$ \\
120 & 0 & $49.5 \pm 12.6$ & $25.7 \pm 10.3$ & $0.4 \pm 1.3$ & $0.52 \pm 0.14 \mathrm{c}$ \\
130 & 0 & $73.9 \pm 9.8$ & $20.7 \pm 5.3$ & $0.7 \pm 2.1$ & $0.26 \pm 0.10 \mathrm{de}$ \\
\hline
\end{tabular}

${ }^{\mathrm{a}}$ Cycle values followed by the same letter within a column are not significantly different at $\alpha=0.05$ (Duncan's multiple-range test). 


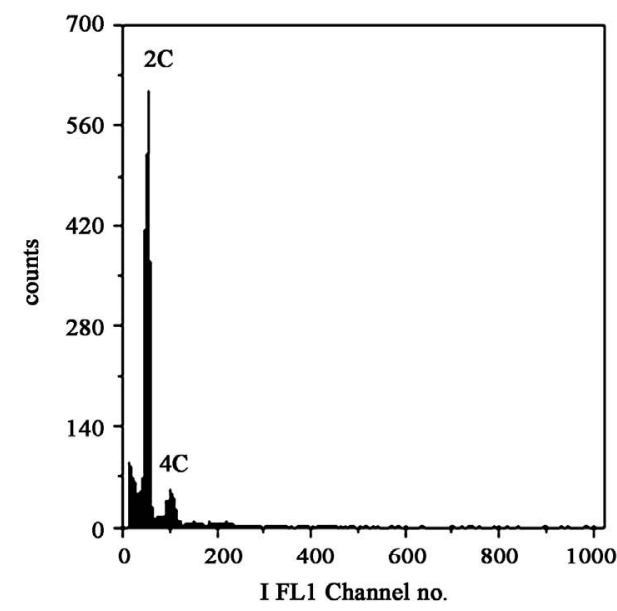

(a)

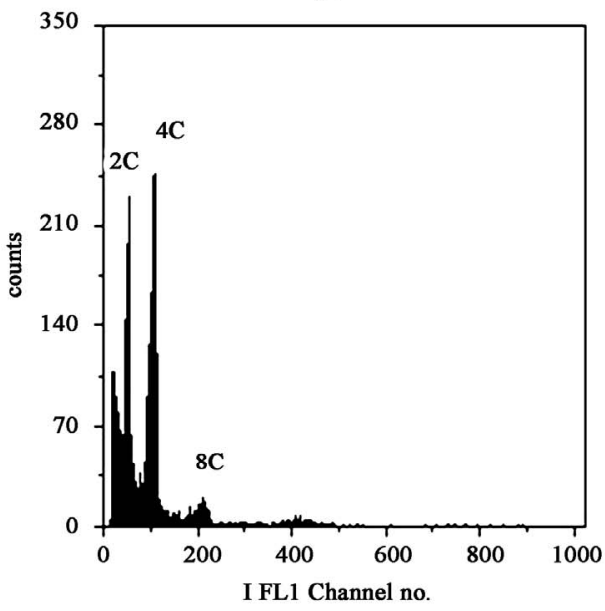

(c)

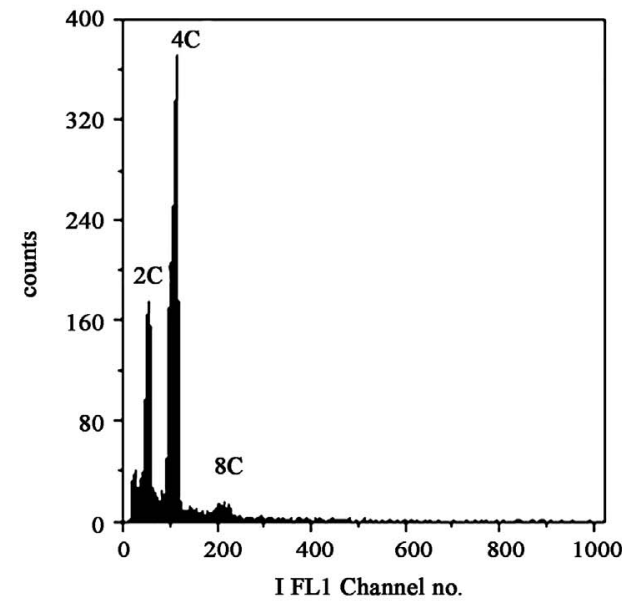

(b)

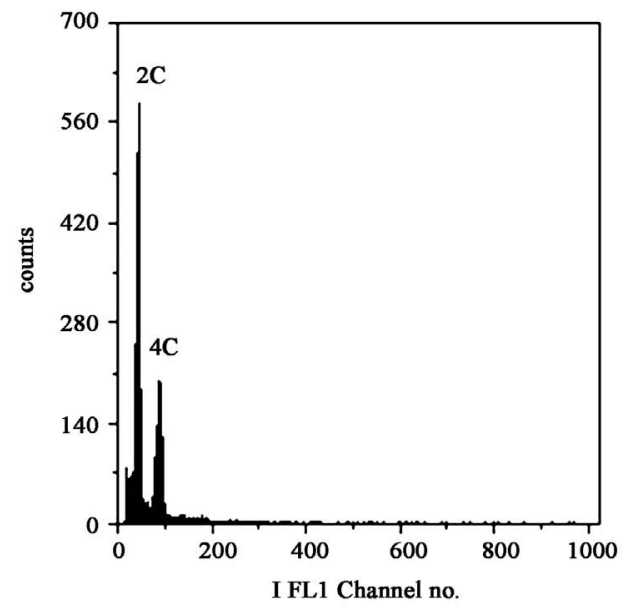

(d)

Figure 2. Flow cytometric histograms of nuclei distribution in ovular tissues of Phalaenopsis aphrodite at different days after pollination (DAP): (a) at 35 DAP; (b) at 57 DAP; (c) at 99 DAP; (d) at 120 DAP.

\subsection{Protocorm Development and Nuclear DNA Contents during Seed Germination}

The mature seed of Phalaenopsis aphrodite subsp. formosana, observed under the dissecting microscope, was composed of a yellow embryo proper and a transparent seed coat (Figure 3(a)). At 4 days after sowing (DAS), the embryo proper expanded, and the seed coat broke after 10 DAS. White absorbing hairs appeared at the base of the protocorm by 20 DAS (Figure 3(b)). Frequency distributions of nuclei having different ploidy levels in protocorms at different stages of development after seed germination are shown in Table 2. Nuclei having 4C and 8C DNA contents were observed at 4 DAS and afterward. As the DAS increased, there was a tendency for $2 \mathrm{C} \mathrm{nu-}$ clei to decrease and for $8 \mathrm{C}$ nuclei to increase. Nuclei with 16C nuclear DNA content appeared after 30 DAS. The percentages of $4 \mathrm{C}$ nuclei remained almost the same at moderate levels throughout development. The occurrence of high percentages of $4 \mathrm{C}$ and $8 \mathrm{C}$ nuclei indicated that endoreduplication took place early in germination. The cycle values increased gradually from 0.48 to 0.69 as the DAS increased (Table 2).

The optical sectioning of the seeds and protocorms was examined by an inverted fluorescence microscope equipped with the Apo Tome Slider system. The largest nuclei were found at the basal region of the embryo in the seeds before sowing (Figure 3(c)). These large nuclei were found mostly in the region $4.55 \mu \mathrm{m}$ beneath the seed coat. They occupied about three-quarters of the total length of the embryo, while the rest of the embryo was occupied by smaller nuclei. A similar situation was observed in the protocorm at 20 DAS (Figure 3(d)). Cells with large nuclei were located in the basal portion of the protocorm, in the region about $7.15 \mu \mathrm{m}$ beneath the surface. 

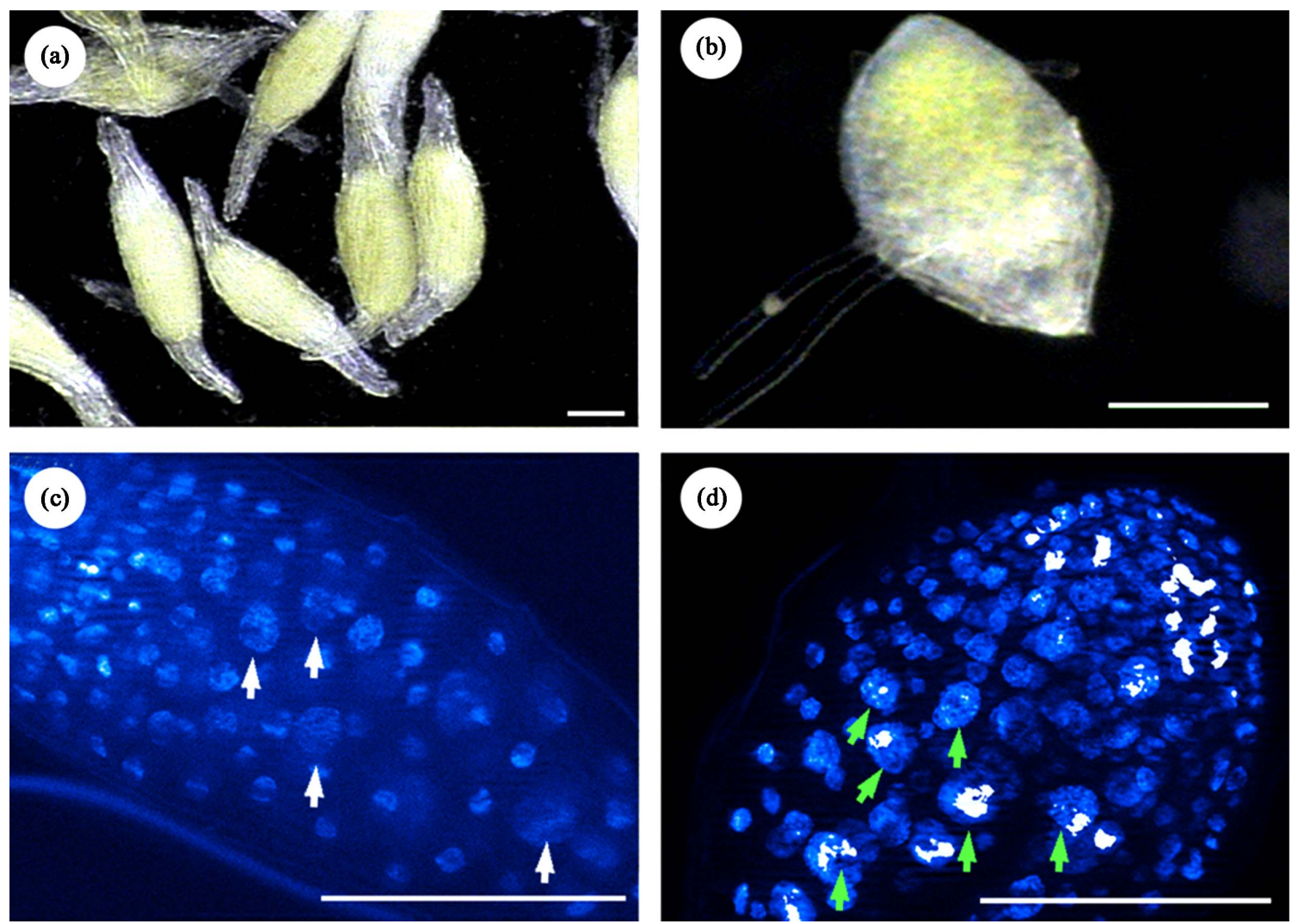

Figure 3. Micrographs of seed and protocorm development of Phalaenopsis aphrodite at different days after seed sowing (DAS): (a) light micrograph of mature seeds before sowing; (b) protocorm at 20 DAS; (c) DAPI-stained fluorescence micrograph of the optical section $4.55 \mu \mathrm{m}$ depth within the seed at 140 DAP before sowing, arrows showing large nuclei; (d) DAPI-stained image of the optical section at $7.15 \mu \mathrm{m}$ depth within the protocorm at 20 DAS, arrows showing large nuclei (bar $=\mathbf{1 0 0} \mu \mathrm{m})$.

Table 2. Percentages of nuclei with various nuclear DNA contents and cycle values of the protocorms of Phalaenopsis aphrodite at different days after sowing (DAS). All values are means \pm SD of 10 replications.

\begin{tabular}{cccccc}
\hline DAS & $2 \mathrm{C}$ & $4 \mathrm{C}$ & $8 \mathrm{C}$ & $16 \mathrm{C}$ & Cycle value $^{\mathrm{x}}$ \\
\hline 4 & $55.5 \pm 5.8$ & $41.3 \pm 4.5$ & $3.3 \pm 4.5$ & 0 & $0.48 \pm 0.09 \mathrm{c}$ \\
10 & $56.2 \pm 3.3$ & $34.4 \pm 2.8$ & $9.4 \pm 2.2$ & 0 & $0.53 \pm 0.05 \mathrm{c}$ \\
20 & $53.0 \pm 3.7$ & $35.0 \pm 2.7$ & $12.1 \pm 2.8$ & 0 & $0.59 \pm 0.06 \mathrm{bc}$ \\
30 & $49.5 \pm 3.1$ & $34.7 \pm 3.2$ & $12.6 \pm 1.9$ & $3.2 \pm 3.5$ & $0.69 \pm 0.11 \mathrm{ab}$ \\
40 & $44.1 \pm 2.5$ & $37.3 \pm 2.3$ & $14.1 \pm 2.4$ & $4.6 \pm 2.5$ & $0.79 \pm 0.06 \mathrm{a}$ \\
\hline
\end{tabular}

${ }^{\mathrm{x}}$ Cycle values followed by the same letter within a column are not significantly different at $\alpha=0.05$ (Duncan's multiple-range test).

\section{Discussion}

Ovary development of Phalaenopsis orchids is pollination dependent, and the growth pattern is biphasic [22]. This kind of developmental pattern is also true in the flowers of Phalaenopsis aphrodite, as shown in our study. Our observations showed that two factors initiated the growth and development of the ovary: pollination, and meiosis of the megaspores and fertilization. Rapid growth of the ovary and extensive differentiation of the ovular tissue after pollination, as well as the dominance of $2 \mathrm{C}$ nuclei over 4C nuclei before $50 \mathrm{DAP}$, suggests that the growth of the ovular tissue might come from rapid cell division as in the normal cell cycle. In addition, $1 \mathrm{C} \mathrm{nu-}$ clei appeared between 43 and 50 DAP, indicating the 
occurrence of meiosis in the megaspores and the entrance of pollen tubes into the ovules. Fertilization might take place immediately after this stage because $1 \mathrm{C}$ nuclei were not found in the later stages of development. As in other angiosperms, the ovule of the Phalaenopsis orchid mainly consists of integuments, the nucellus and the megaspore, which becomes the embryo sac after fertilization. Through a series of cytological studies, Zhang and O'Neill [22] showed that the growth of the ovule at this stage is mainly due to an increase in the number of cells in the peripheral tissues surrounding the megagametophyte, i.e., the integuments and nucellus. Similar to other actively growing tissues such as the shoot tip in seedlings of Brassica species [26], endopolyploidy did not occur at the early stage of ovule development in Phalaenopsis aphrodite before pollination. Evidence of low level of endoreduplication was also indicated by the low cycle values $(0.14-0.15)$ at this stage. An organ with a cycle value below 0.1 was not considered to have endoreduplication [10].

After fertilization and the formation of the embryo sac, the growth pattern of the ovule changed. Besides the morphological changes in the ovules, the distribution of the nuclei changed from being evenly distributed early in development to being localized in the embryo when the seed became mature. Flow cytometric analysis indicated that $4 \mathrm{C}$ nuclei increased rapidly after fertilization, maintained at a high level and then decreased by the time of seed maturation. These $4 \mathrm{C}$ nuclei might come from two possible sources: $\mathrm{G} 2$ nuclei of cells having $2 \mathrm{C}$ nuclear DNA content in the normal mitotic cycle and G1 nuclei of cells derived from first endoreduplication of $2 \mathrm{C}$ nuclei [6]. Right after fertilization, rapid nuclear and cell division might occur in the cells of the pro-embryo and the peripheral tissues, including the integuments and nucellus. Because of the extensive synthesis and duplication of DNA during S- and G2-phases of the cell cycle, 4C nuclei increased rapidly at this stage of development. Comparison of the nuclei distribution of the ovular structure at 50 and 57 DAP (Figures 1(c) and (d)) indicated that the early stage of seed development was mainly through the increase in the number of cells. The growth of seeds of Phalaenopsis aphrodite included the development of seed coat from the integuments, suspensor cells and the embryo proper. While the embryos continued to grow by cell division, the cells of the integuments and suspensors elongated and became differentiated tissues to perform their specific function [23]. The nuclei of these differentiated cells might shift to the endoreduplication cycle and maintained as $4 \mathrm{C}$ nuclei. The occurrence of small amount of $8 \mathrm{C}$ nuclei during seed development (Table 1) and relative high level of cycle values supported that part of the $4 \mathrm{C}$ nuclei were the G1 nuclei resulted from endoreduplication. Occurrence of endopolyploidy in integuments and suspensors during seed development have also been reported in other plant species $[5,27,28]$. When the seeds of Phalaenopsis aphrodite became mature, the inner integument and suspensor degenerated, while the outer integument turned into the shrivelled seed coat [23]. This process would result in the decrease in the proportion of $4 \mathrm{C}$ and $8 \mathrm{C}$ nuclei in the seed at this stage as shown in our data. From these observations, endopolyploidy in cells of the integument and suspensor might play a role not only in the expansion of the size of ovules, but also as transitional tissue for nutrient storage and transfer for the growth of the embryo as the seeds mature $[5,23,27,29]$. Direct evidence of the occurrence of endoreduplicated nuclei in these cells is worthy for further investigation.

In this study, observations of $8 \mathrm{C}$ nuclei at $4 \mathrm{DAS}$ and $16 \mathrm{C}$ nuclei at $10 \mathrm{DAS}$ provide evidence for endopolyploidy at the early stage of seed germination in Phalaenopsis aphrodite. The level of endopolyploidy increased as the protocorms developed. Similar observation was also reported in Vanda orchid [16]. However, the occurrence of endopolyploidy in the protocorm at 4 DAS in this study is the earliest comparing to other studies on the development of protocorms of other orchids [16-18].

Although the embryos in the seeds of Phalaenopsis orchid lacked the defined tissue pattern observed in other flowering plants, smaller cells were seen in the apical zone of the embryo proper in the mature seeds of Phalaenopsis aphrodite [23]. Large nuclei located at the basal portion of mature seeds and developing protocorms were observed in this study. Together with the data of the flow cytometry, these cells containing large nuclei would be the result of endopolyploidy since cell size was shown to be positively correlated with the degree of endopolyploidy $[5,13,14,19]$. In addition, we also found a higher frequency of endopolyploid nuclei in the basal portion of the protocorms than that in the apical portion which contained the meristem [30]. The occurrence of endopolyploidy in the seeds of Phalaenopsis aphrodite before germination might be an early indication of tissue differentiation of the embryo making this group of orchids easy to germinate, as in Epidendron ibaguense [23]. In a study of the developing embryo of Vanda sanderiana after germination [20] a gradient of small to large nuclei was observed from the meristematic region to the posterior suspensor region. The amount of DNA in the nuclei was shown to increase in direct proportion to the distance of the nuclei from the meristem. The author proposed that the posterior region of the protocorm was part of the embryo differentiated to serve as the absorbing organ for 
the transfer of nutrients, as in the endosperm of the albuminous seeds. Our observation of the early occurrence of endopolyploidization in protocorm development would suggest a role of endopolyploidy similar to that in Vanda sanderiana [20].

In conclusion, this study showed that different distribution patterns of nuclei of different ploidy levels occurred in ovules after fertilization; in mature seeds before germination and in early protocorm development in $P h$ alaenopsis aphrodite. The occurrence of endopolyploidy during embryo development of the seed and at early stage of protocorm development might perform specific functions related to organ differentiation. Further studies of the role of endopolyploidy during the development of seeds and protocorms of Phalaenopsis orchids are worthy to be pursued.

\section{Acknowledgements}

The authors would like to thank Miss W. W. Liu for her preliminary investigation of this study. This research was supported by the National Science Council, Taiwan (NSC96-2317-B-390-004; NSC-99-2324-B-390- 002-CC1).

\section{REFERENCES}

[1] G. Grafi, "Cell Cycle Regulation of DNA Replication: The Endoreduplication Perspective," Experimental Cell Research, Vol. 244, No. 2, 1998, pp. 372-378. doi:10.1006/excr.1998.4213

[2] S. van den Heuvel, "Cell-Cycle Regulation," WormBook, The C. elegans Research Community, 2005.

[3] D. Francis, "The Plant Cell Cycle: 15 Years on," New Phytologist, Vol. 174, No. 2, 2007, pp. 261-278. doi:10.1111/j.1469-8137.2007.02038.x

[4] B. A. Larkins, B. P. Dilkes, R. A. Dante, C. M. Coelho, Y. M. Woo and Y. Liu, "Investigating the Hows and Whys of DNA Endoreduplication," Journal of Experimental Botany, Vol. 52, No. 355, 2001, pp. 183-192. doi:10.1093/jexbot/52.355.183

[5] M. Barow, "Endopolyploidy in Seed Plants," BioEssays, Vol. 28, No. 3, 2006, pp. 271-281.

[6] D. P. Biradar, A. Lane Rayburn and D. G. Bullock, "Endopolyploidy in Diploid and Tetraploid Maize (Zea mays L.)," Annals of Botany, Vol. 71, No. 5, 1993, pp. 417-421. doi:10.1006/anbo.1993.1053

[7] M. J. M. Smulders, W. Rus-Kortekaas and L. J. W. Gilssen, "Development of Polysomaty during Differentiation in Diploid and Tetraploid Tomato (Lycopersicon esculentum) Plants," Plant Science, Vol. 97, No. 1, 1994, pp. 53-60. doi:10.1016/0168-9452(94)90107-4

[8] K. A. Pyke, L. L. Marrison and R. M. Leech, “Temporal and Spatial Development of the Cells of the Expanding First Leaf of Arabidopsis thaliana (L.) Heynh.," Journal of Experimental Botany, Vol. 42, No. 11, 1991, pp. 1407-1416. doi:10.1093/jxb/42.11.1407
[9] P. D. Griffiths, H. J. Ougham and R. N. Jones, "Genotypic and Environmental Effects on Endopolyploidy in the Epidermal Tissues of Lolium perenne L. and Lolium multiflorum Lam," New Phytologist, Vol. 128, No. 2, 1994, pp. 339-345. doi:10.1111/j.1469-8137.1994.tb04018.x

[10] M. Barow and A. Meister, "Endopolyploidy in Seed Plants is Differently Correlated to Systematics, Organ, Life Strategy and Genome Size," Plant, Cell \& Environment, Vol. 26, No. 4, 2003, pp. 571-584. doi:10.1046/j.1365-3040.2003.00988.x

[11] W. Nagl, "DNA Endoreduplication and Polyteny Understood as Evolutionary Strategies," Nature, Vol. 261, 1976, pp. 614-615.

[12] F. D'Amato, "Chromosome Endoreduplication in Plant Tissue Development and Function," In: J. A. Bryant and D. Chiatante, Ed., Plant Cell Proliferation and Its Regulation in Growth and Development, John Wiley \& Sons, Chichester, 1998, pp. 153-166.

[13] N. Kudo and Y. Kimura, "Nuclear DNA Endoreduplication during Petal Development in Cabbage: Relationship between Ploidy Levels and Cell Size," Journal of Experimental Botany, Vol. 53, No. 371, 2002, pp. 1017-1023. doi:10.1093/jexbot/53.371.1017

[14] G. Jovtchev, V. Schubert, A. Meister, M. Barow and I. Schubert, "Nuclear DNA Content and Nuclear and Cell Volume Are Positively Correlated in Angiosperms," Cytogenetic and Genome Research, Vol. 114, No. 1, 2006, pp. 77-82.

[15] S. Lin, H. C. Lee, W. H. Chen, C. C. Chen, Y. Y. Kao, Y. M. Fu, Y. H. Chen and T. Y. Lin, "Nuclear DNA Contents of Phalaenopsis sp. and Doritis pulcherrima," Journal of the American Society for Horticultural Science, Vol. 126, No. 2, 2001, pp. 195-199.

[16] W. L. Lim and C. S. Loh, "Endopolyploidy in Vanda Miss Joaquim (Orchidaceae)," New Phytologist, Vol. 159, No. 1, 2003, pp. 279-287. doi:10.1046/j.1469-8137.2003.00797.x

[17] M. Yang and C. S. Loh, "Systemic Endopolyploidy in Spathoglottis plicata (Orchidaceae) Development," BMC Cell Biology, Vol. 5, 2004, p. 33. doi:10.1186/147-2121-5-33

[18] W. H. Chen, C. Y. Tang and Y. L. Kao, "Ploidy Doubling in Vitro Culture of Excised Protocorms or Protocorm-Like Bodies in Phalaenopsis Species," Plant Cell, Tissue and Organ Culture, Vol. 98, No. 2, 2009, pp. 229-238. doi:10.1007/s 11240-009-9557-3

[19] H. C. Lee, D. W. Chiou, W. H. Chen, A. H. Markhart, Y. H. Chen and T. Y. Lin, "Dynamics of Cell Growth and Endoreduplication during Orchid Flower Development," Plant Science, Vol. 166, No. 3, 2004, pp. 659-667. doi:10.1016/j.plantsci.2003.10.034

[20] M. R. Alvarez, "Quantitative Changes in Nuclear DNA Accompanying Postgermination Embryonic Development in Vanda (Orchidaceae)," American Journal of Botany, Vol. 55, No. 9, 1968, pp. 1036-1041.

doi: $10.2307 / 2440469$ 
[21] J. A. Nadeau, X. S. Zhang, J. Li and S. D. O’Neill, "Ovule Development: Identification of Stage-Specific and Tissue-Specific cDNAs," The Plant Cell, Vol. 8, No. 2, 1996, pp. 213- 239.

[22] X. S. Zhang and S. D. O’Niell, “Ovary and Gametophyte Development Are Co-Ordinately Regulated by Auxin and Ethylene Following Pollination," The Plant Cell, Vol. 5, No. 4, 1993, pp. 403-418.

[23] Y. I. Lee, E. C. Yeung, N. Lee and M. C. Chung, "Embryology of Phalaenopsis amabilis var. formosa: Embryo Development," Botanical Studies, Vol. 2, 2008, pp. 139146.

[24] T. Murashige and F. Skoog, "A Revised Medium for Rapid Growth and Bioassays with Tobacco Tissue Culture," Physiologia Plantarum, Vol. 15, No. 3, 1962, pp. 473-497. doi:10.1111/j.1399-3054.1962.tb08052.x

[25] W. T. Tsai, W. H. Chen, R. M. Hsieh, M. S. Chyou and C. C. Wu, "An Important Factor Affecting the Germination and Growth of Phalaenopsis Seeds," In: S. Huang, S. Hsieh and T. Liu, Ed., The Impact of Biological Research on Agricultural Productivity, Taichung District Agricultural Improvement Station-Taichung, Taiwan, 1992, pp. 219-228.
[26] N. Kudo and Y. Kimura, "Flow Cytometric Evidence for Endopolyploidy in Seedlings of Some Brassica Species," Theoretical and Applied Genetics, Vol. 102, No. 1, 2001, pp. 104-110. doi:10.1007/s001220051624

[27] E. C. Yeung and D. W. Meink, "Embryogenesis in Angiosperms: Development of the Suspensor," The Plant Cell, Vol. 5, No. 10, 1993, pp. 1371-1381. doi: $10.2307 / 3869789$

[28] A. Kladnik, P. S. Chourey, D. R. Pring and M. Dermastia, "Development of the Endosperm of Sorghum bicolor during the Endoreduplication-Associated Growth Phase," Journal of Cereal Science, Vol. 43, No. 2, 2006, pp. 209-215. doi:10.1016/j.jcs.2005.09.004

[29] K. Robinson-Beers, R. E. Pruitt and C. S. Gasser, "Ovule Development in Wild-Type Arabidopsis and Two Female-Sterile Mutants," The Plant Cell, Vol. 4, No. 10, 1992, pp. 1237-1249.

[30] W.-H. Chen, C.-Y. Tang, T.-Y. Lin, Y.-C. Weng and Y.-L. Kao, "Changes in the Endopolyploidy Patterns of Different Tissues in Diploid and Tetraploid Phalaenopsis aphrodite subsp. formosana (Orchidaceae)," Plant Science, Vol. 181, No. 1, 2011, pp. 31-38. doi:10.1016/j.plantsci.2011.03.006 